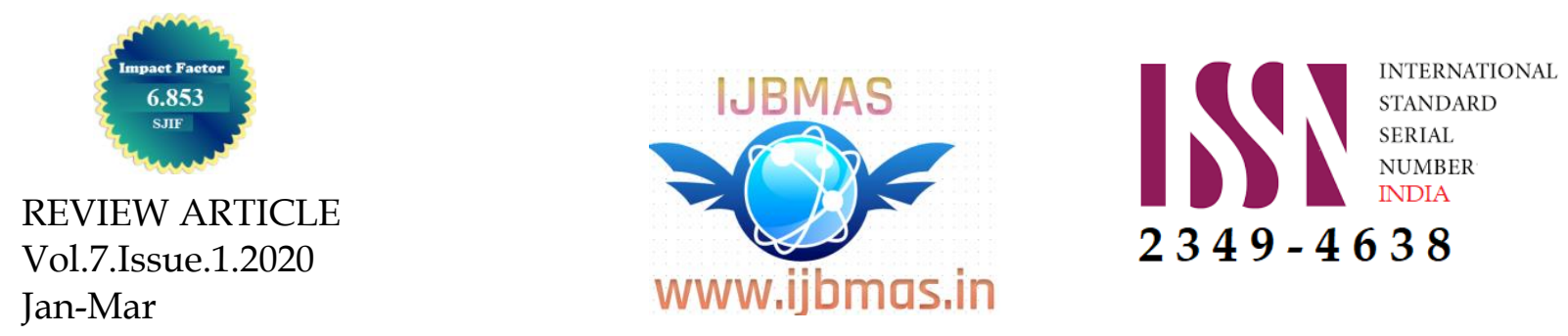

INTERNATIONAL JOURNAL OF BUSINESS, MANAGEMENT AND ALLIED SCIENCES (IJBMAS)

A Peer Reviewed and refereed Journal

\title{
DELVING INTO THE FACTS AROUND AUTOMOTIVE REVOLUTION
}

\author{
VAHNICA YADAV \\ Student II MBA, Shri Vishnu Engineering College for Women, Bhimavaram. \\ DOI: $\underline{10.33329 / \mathrm{ijbmas} .7 .1 .21}$
}

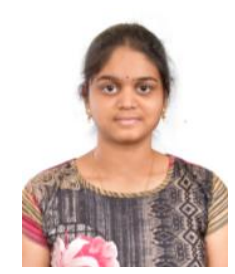

VAHNICA YADAV

\begin{abstract}
In brief, the essence of this article, gives us an idea about the facts regarding the "Automotive Revolution". A solution to the turmoil, whether to worry about or celebrate the "Rise Of Machines", can be found through some facts.

And yes, the most beneficial professionals from this revolution would be Managerial Graduates. Statistics of some surveys convey such positive signals to the would-be managers with magical numbers.
\end{abstract}

\section{CONCEPT IN DEPTH}

Vary recently we have entered the game-changing decade in which, organizations all over the world are focused on reducing costs through Artificial Intelligence, whereas in contrast both the budding and established professionals are worried about losing their jobs with rise of the same.

The RISE OF MACHINES would take over the place of man at work. But this would become an illusion in some cases, particularly in the case of MANAGERS.We as a part of this Internetgeneration must gear up for the challenges ahead.

JACK MA, the founder of Alibaba, spoke about the impact of this technological revolution on our thought and work. He also threw a strong light on the fact that a different skill-set is necessary to survive and eventually succeed in these harsh conditions.

As far as the conventional education is concerned, the focus of it is mainly on providing standardized information. Highly specialized skill-courses like Engineering, law etc... produces professionals through focused career. On the contrary, MBA is a versatile course which covers a wide range of skills constituting both technical type of skills like Finance, Operations, Logistics along with social skills like Organizational behavior, communication etc...And here lies the competitive advantage of this course in the prevailing conditions.

The Global Human Capital Trends 2019 report states that "The future workplace would witness a shift from JOBS to SUPERJOBS." And these super jobs would require a perfect blend of 
technical and analytical skills with soft human skills. The workforce must be effective in problem solving and have the ability to create new knowledge.

In contrast to the in secured feeling, that millions of jobs would become obsolete, AI surprisingly creates jobs which are more meaningful, value adding and highly paying, provided we develop a different skill-set.

The probability of a job being automated is estimated by a study made by a website "Will Robots Take My Job". This study states that many technical jobs including high skilled job roles like accountants and auditors are highly sensitive to automation, i.e. almost about $94 \%$. On the other hand, managerial positions like Sales manager, Marketing manager, Human resource manager, Finance manager etc... are at a less than $10 \%$ susceptibility to automation. More specifically, the Human resource manager role has very less susceptibility i.e. $0.6 \%$ to automation.

The reason behind this is that such type of roles require not only technical skills, but also very important qualities like empathy, emotional intelligence, inter-personnel skills, etc.. Which are difficult for a machine to adapt and execute.

Leadership is also impossible to be automated, because machines can't inspire people and direct people. All these facts indirectly conveys the greater demand for HYBRID JOBS, which are synonymous to the SUPERJOBS mentioned above.

Good Business-schools understood the need to update according to the se future requirements and started offering new age courses like AI, Machine learning, analytical courses like predictive modeling, Risk analytics etc... along with equally important life skills like communication, ethics etc...

Even workshops are being conducted to enhance experiential learning of these skills along with entrepreneurial thinking, innovation etc...

Premiere B-schools are providing proper platform for rural, social and even international immersion. All these initiatives by the institutions produce professionals with greater values, who not only work for their personal growth, but also contribute a lot to social welfare.

\section{CONCLUSION}

In order to prepare for future, students and professionals must be Intelligent, Emotionally balanced and strong. The most unique advantage of Man, which differentiates him from machine is LOVE and RESPECT towards the society. This fact cannot be ignored and is very important to sustain in the future work conditions and succeed, despite the great automotive revolution, along with an inclination to ENDLESS LEARNING with a greater emphasis on HUMAN VALUES and ETHICS.

\section{REFERENCES}

https://www.aceable.com/blog/how-the-invention-of-the-car-changed-the-world/

https://www.whichcar.com.au/car-advice/citroen-history-trivia-fast-facts

https://home.kpmg/content/dam/kpmg/pdf/2013/10/self-driving-cars-are-we-ready.pdf

https://www.britannica.com/technology/automotive-industry

https://www.statista.com/topics/1487/automotive-industry/ 